Research Article

\title{
Antibacterial and Catalytic Efficacy of Biosynthesized Silver Nanoparticles Using Marine Seaweed Padina Tetrasromatica
}

\author{
Kaithavelikkakath Francis Princy ${ }^{1}$, Sarasan Manomi $^{2}$, Rosamma Philip ${ }^{2}$, Anu Gopinath ${ }^{3}$ \\ ${ }^{1}$ Department of Chemistry, St. Albert's College, Ernakulam, Kerala, India \\ ${ }^{2}$ Department of Marine Biology, Microbiology and Biochemistry, School of Marine Sciences, Cochin University of Science and \\ Technology, Kerala, India \\ ${ }^{3}$ Department of Fishery Hydrography, Kerala University of Fisheries and Ocean Studies, Cochin, India \\ Corresponding author: E-mail: princykf@gmail.com; anugowri@hotmail.com
}

Received: Dec. 16, 2015; Accepted: Feb. 18, 2016; Published: Mar. 12, 2016.

Citation: Kaithavelikkakath Francis Princy, Sarasan Manomi, Rosamma Philip and Anu Gopinath. Antibacterial and Catalytic Efficacy of Biosynthesized Silver Nanoparticles Using Marine Seaweed Padina Tetrasromatica. Nano Biomed. Eng. 20I6 8(I), I6-23.

DOI: $10.5101 /$ nbe.v8il.p16-23.

\begin{abstract}
Utilization of renewable marine resources for the biosynthesis of metal nanoparticles is an innovative area in the current nanotechnology research. The present article reports a simple environmentally benign method for the synthesis of silver nanoparticles using aqueous extract of marine brown seaweed Padina Tetrastromatica, which act as both the reducing and stabilising agent. The formation, morphology and crystalline nature of the synthesised silver nanoparticles were determined using UVVisible Spectroscopy, Transmission electron microscopy, Selected area electron diffraction and X-ray diffraction techniques. The surface plasmon resonance peak at $424 \mathrm{~nm}$ in the UV-Visible spectrum confirmed the formation of silver nanoparticles. The biosynthesised silver nanoparticles were almost spherical with an average size of $15 \mathrm{~nm}$. Crystalline nature of silver nanoparticles is evident from the characteristic peaks in the X-ray diffraction pattern, bright circular spots in the selected area electron diffraction pattern and clear lattice fringes in the High resolution Transmission electron microscopy images. Fourier transform infrared spectroscopic analysis revealed the presence of functional bio active metabolites in seaweed extract which is responsible for the formation and efficient stabilization of the nanoparticles. The biosynthesised silver nanoparticles show excellent antimicrobial activity against Escherichia coli and Aeromonas hydrophila. They also show very good catalytic activity for the reduction of methylene blue in the presence of $\mathrm{NaBH} 4$ in aqueous medium. Thus the green synthesised nanoparticles are expected to be a promising candidate for the application in diverse fields.
\end{abstract}

Keywords: Biosynthesis; Silver nanoparticles; Padina Tetrastromatica; Catalysis; Methylene Blue Antibacterial activity

\section{Introduction}

Metal nanoparticles are gaining lot of significance for the past few years due to their unusual and fascinating properties, with tremendous applications in diverse areas such as catalysis, optics, sensing, biological imaging and antimicrobials [1]. Among the several metal nanoparticles, silver nanoparticles (AgNPs) have gained considerable attraction in view of their unique properties like good thermal conductivity, 
electrical conductivity, chemical stability, catalytic and antibacterial activity [2]. Various physical and chemical methods have been employed in the synthesis of silver nanoparticles. But they are considered hazardous owing to the use of toxic chemicals as reducing and stabilizing agents which creates serious environmental problems and cause adverse effects in its applications. Hence the biosynthesis of nanoparticles especially using plants has gained a great importance in recent times as it is eco-friendly, simple, cost effective and thus can be easily scaled up for large scale synthesis. There are several reports on the biosynthesis of nanoparticles using terrestrial plants [3-6]. However utilization of renewable marine resources like marine seaweeds in the nanoparticle synthesis is yet to be explored.

Silver in the form of nanoparticles could be more reactive than their bulk counterparts due to their large surface area to volume ratio. As a result they can penetrate into the cell membranes leading to the accumulation of intracellular nanoparticles which can cause malfunctioning of cells. Thus they can effectively hinder the microbial growth [7]. The AgNPs have been reported to be very effective against various bacteria, viruses, fungi and other eukaryotic microorganisms at very low concentrations [8].

Disposal of dye effluents from various industries into water bodies result in significant environmental pollution. They inhibit sunlight penetration, thereby hindering photosynthesis and perturb the aquatic life [9]. Moreover many of these dyes are found to be mutagenic and carcinogenic and hence harmful to human beings [10]. Therefore it is essential to remove these dyes from our water resources. Due to the chemical stability of dye pollutants, the traditional water treatment techniques are found to be ineffective for their removal. Recently, nanocatalysis has emerged as an alternative to conventional water treatment methods. The small size, large surface area to volume ratio and size dependent reactivity have made metal nanoparticles an efficient catalyst [11]. The potential catalytic activity of metal nanoparticles in the degradation of certain dye stuffs have been reported recently $[12,13]$.

Thus the present article reports an environmentally benign and unexploited method for the synthesis of silver nanoparticles using aqueous extract of brown seaweed Padina Tetrastromatica, which is a potential source of bioactive metabolites like flavonoids, quinones, terpenoids and steroids [14]. The seaweed extract has a dual effect as it act as reducing agents of silver ions and as stabilizing agents for the formed silver nanoparticles [15]. The antibacterial effect of the biosynthesized AgNPs was evaluated against two gram negative bacteria Escherichia coli (E.coli) and Aeromonas hydrophila (A.hydrophila) using KirbyBauer disc diffusion method. Further, the catalytic potential of the biosynthesized AgNPs was evaluated using the reduction reaction of methylene blue by $\mathrm{NaBH}_{4}$ using UV-Visible spectroscopy.

\section{Materials and methods}

\section{Materials}

Silver nitrate $(99.9 \%)$ was purchased from Sigma Aldrich. Methylene blue and $\mathrm{NaBH}_{4}$ of analytical grade were purchased from Merck (India) and used as such. All aqueous solutions were prepared using sterile Milli Q water.

\section{Preparation of Seaweeds Extract}

The seaweed Padina Tetrastromatica was collected during the month of October from the coast of Thirumullavaram $\left(8^{\circ} 53^{\prime} 38^{\prime \prime} \mathrm{N} ; 76^{\circ} 33^{\prime} 14^{\prime \prime} \mathrm{E}\right)$, Kollam district of Kerala. The samples were washed thoroughly with Milli Q water to remove extraneous materials and $10 \mathrm{~g}$ of the washed seaweed was finely cut into small pieces and stirred with $100 \mathrm{~mL}$ sterile Milli Q water for $1 \mathrm{~min}$ and kept in a water bath at $60^{\circ} \mathrm{C}$ for 20 minutes. Finally, the extract was filtered with Whatman No. 1 filter paper and used for further experiments.

\section{Biosynthesis and Characterization of AgNPs}

For the biosynthesis of AgNPs, seaweed extract was mixed with $1 \mathrm{mM} \mathrm{AgNO}$ solution in 1:1 ratio, stirred well for 1 minute and incubated in dark at room temperature under static condition. A control setup was also maintained without seaweed extract. The bioreduction of $\mathrm{AgNO}_{3}$ into AgNPs was periodically monitored using UV-Vis spectrophotometer in a range of wavelengths between 300 and $700 \mathrm{~nm}$. After $48 \mathrm{~h}$ of reaction, the bioreduced reaction mixture was subjected to centrifugation at $15000 \mathrm{rpm}$ for $20 \mathrm{~min}$ at $4{ }^{\circ} \mathrm{C}$. The resulting pellet was redispersed in sterile Milli $\mathrm{Q}$ water and freeze dried. The freeze dried AgNPs were then characterized using UV-Visible Spectroscopy, High 
resolution Transmission electron microscopy (HRTEM), Selected area electron diffraction (SAED), $\mathrm{X}$-ray diffraction (XRD) and Fourier transform infrared spectroscopy (FTIR) techniques. UVVis spectral analysis was carried out using Thermo scientific Evolution 201 Spectrophotometer. FTIR spectrum was recorded on a Perkin Elmer Spectrum 100 at the wavelength range of $4000-550 \mathrm{~cm}^{-1}$. XRD measurement was made on a PANalytic X'PERT-PRO X-ray spectrometer operated at a voltage of $40 \mathrm{kV}$ and a current of $30 \mathrm{~mA}$ with $\mathrm{CuK} \alpha$ radiation $(\lambda=0.1542$ $\mathrm{nm})$. HRTEM images and SAED patterns have been obtained with a Tecnai $\mathrm{G}^{2} 30$ transmission electron microscope.

\section{Antibacterial property of AgNPs}

AgNPs were examined for their inhibitory activity against two gram negative bacterial strains such as E.coli and A.hydrophila using Kirby-Bauer disc diffusion method. Bacterial pathogens were obtained from National Centre for Aquatic Animal Health, Cochin University of Science and Technology, Kochi. A suspension of $6 \mathrm{hr}$ old bacterial strains was swabbed on nutrient agar plates using sterile cotton swabs. Double sterilized filter paper disks $(6 \mathrm{~mm})$ impregnated with $20 \mu \mathrm{l}$ of the nanoparticle suspension $(200 \mu \mathrm{g} /$ $\mathrm{ml})$ was placed on nutrient agar plates aseptically. The plates were incubated at $37{ }^{\circ} \mathrm{C}$ for 24 hours and the diameter of zone of inhibition was recorded.

\section{Catalytic degradation of methylene blue}

To study the catalytic degradation of methylene blue by $\mathrm{NaBH}_{4}, 0.5 \mathrm{~mL}$ of freshly prepared $\mathrm{NaBH}_{4}$ solution $(0.06 \mathrm{M})$ was added to $2 \mathrm{~mL}$ of aqueous methylene blue solution $(0.08 \mathrm{mM})$ in a quartz cuvette. Then 0.5 $\mathrm{mL}$ of silver nanocatalyst solution $(1 \mathrm{mg} / \mathrm{mL})$ was added and the progress of the reaction was monitored using UV-Visible spectrophotometer at regular interval of 2 minutes in the range of $400-850 \mathrm{~nm}$ at room temperature.

\section{Results and Discussions}

\section{Characterization of silver nanoparticles}

The reduction of $\mathrm{AgNO}_{3}$ into $\mathrm{AgNPs}$ during exposure to seaweed extract is visually evident from the colour change of reaction mixture from light yellow to dark brown as a result of the surface plasmon

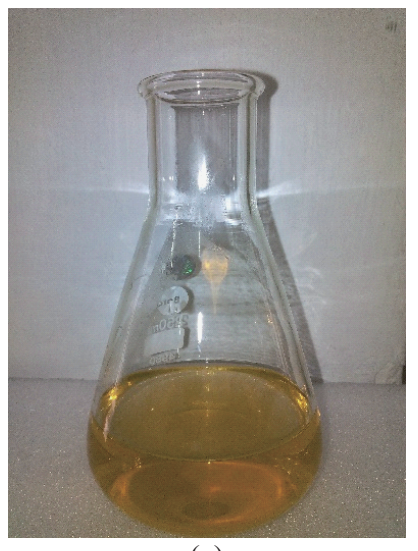

(a)

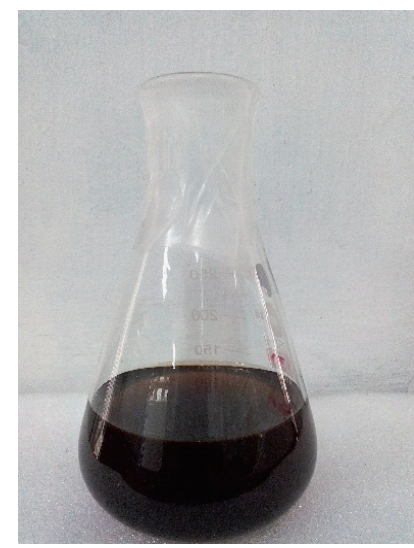

(b)

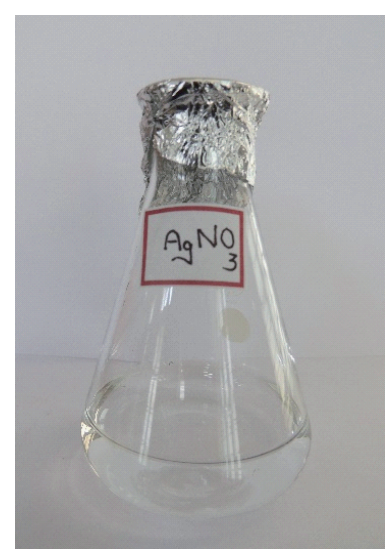

(c)
Fig. 1 Colour intensity of the Padina Tetrastromatica extract incubated with Silver ions (a) at the beginning of reaction, and (b) after $48 \mathrm{~h}$ (c) control $\mathrm{AgNO}_{3}$.

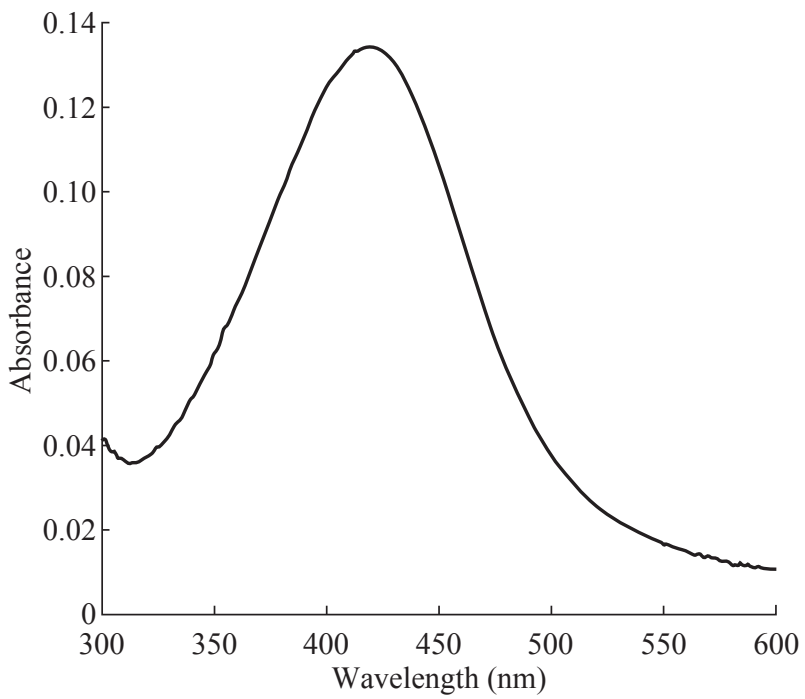

Fig. 2 UV-Visible Spectrum of AgNPs formed using Padina Tetrastromatica.

resonance phenomenon (Fig. 1). The colour change was observed within 15 min indicating the formation of AgNPs and the control $\mathrm{AgNO}_{3}$ solution (without seaweed extract) showed no colour change. UV-visible spectroscopy was used to ascertain the formation of 
metal nanoparticles. In the UV-Vis spectrum (Fig. 2) a sharp intense peak at $424 \mathrm{~nm}$ was observed, which corresponds to the typical surface plasmon resonance of silver nanoparticles [16]. Similarly Kannan et al. [17] reported that the surface plasmon resonance band was located at $422 \mathrm{~nm}$ for AgNPs synthesized using green seaweed Codium capitatum.

HR-TEM image at different magnification (Fig. 3) revealed that the biosynthesised AgNPs were

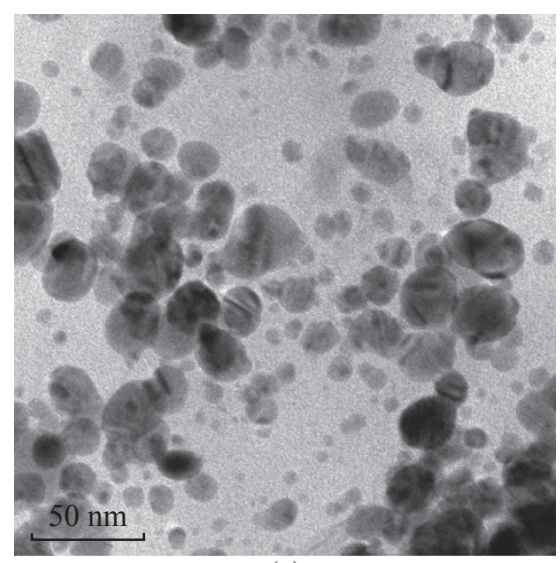

(a)

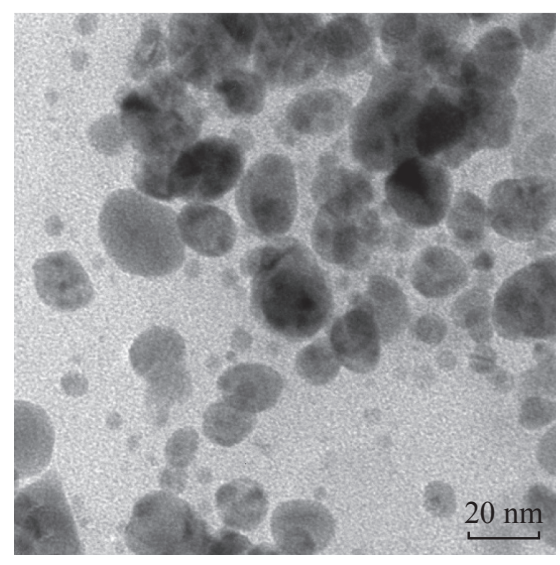

(b)

Fig. 3 (a)-(b) TEM images of AgNPs at different magnifications.

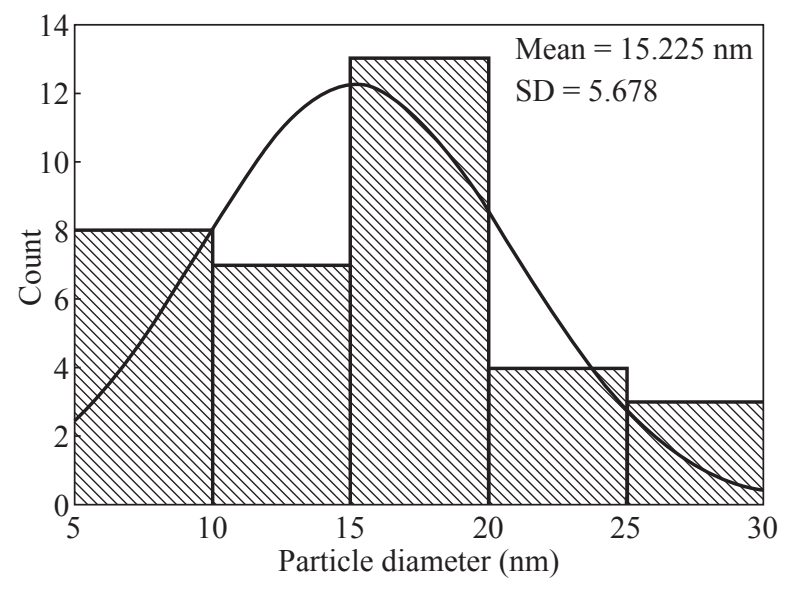

Fig. 4 Particle size histogram of AgNPs. almost spherical in shape. It is observed that there is a variation in particle size. Most of the AgNPs ranged from $5-35 \mathrm{~nm}$. From the histogram representing the size distribution of the particles (Fig. 4), the average size of AgNPs was found to be $\approx 15 \mathrm{~nm}$. Crystalline nature of the nanoparticles is evidenced by the lattice fringes in the HR-TEM image (Fig. 5) and SAED pattern (Fig. 6) with bright circular spots.

The X-ray diffraction confirmed the crystalline nature of silver nanoparticles The XRD spectrum of biosynthesized AgNPs (Fig. 7) gave characteristic peaks at $2 \theta$ values of $38.26^{\circ}, 44.33^{\circ}, 64.66^{\circ}$ and $77.58^{\circ}$ which can be indexed to the (lll 111$),\left(\begin{array}{lll}2 & 0 & 0\end{array}\right),\left(\begin{array}{lll}2 & 2 & 0\end{array}\right)$ and $\left(\begin{array}{lll}3 & 1 & 1\end{array}\right)$ reflections of fcc structure of metallic silver (JCPDS file No. 04-0783). The broad nature of XRD peaks could be attributed to the nanocrystalline nature of AgNPs. Similar appearance of diffraction patterns are observed with AgNPs synthesized using Melia

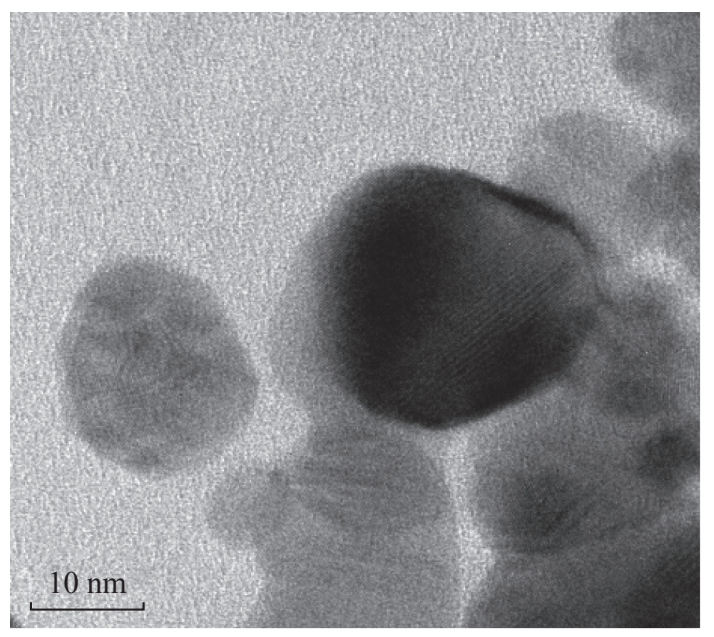

Fig. 5 HR-TEM image of AgNPs.

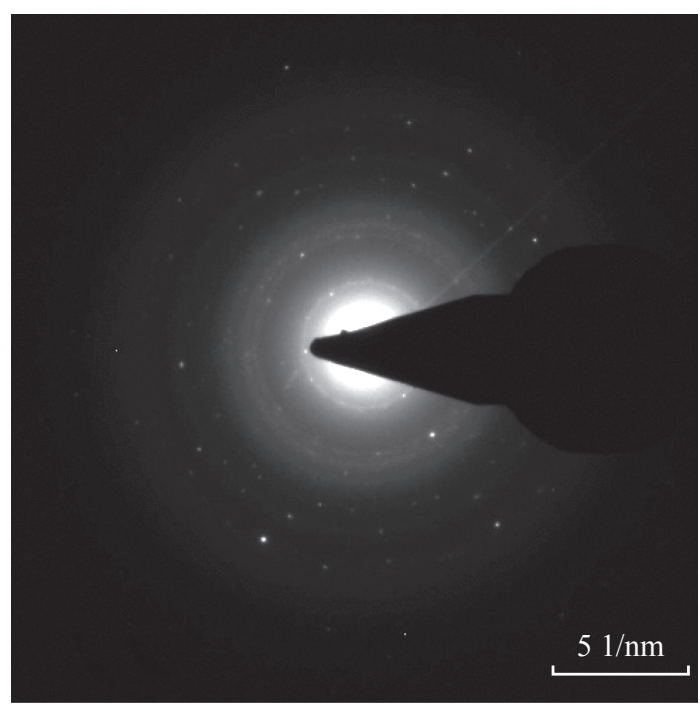

Fig. 6 SAED pattern. 


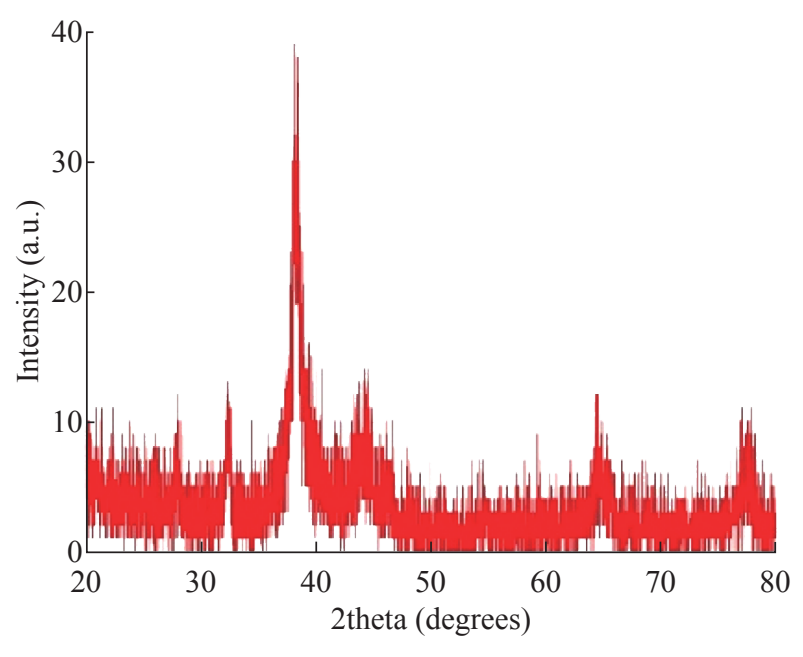

Fig. 7 XRD pattern of AgNPs.

dubia leaf extract [18]. The average crystalline size of the biosynthesised AgNPs was determined using Debye-Scherrer equation,

$\mathrm{D}=\mathrm{K} \lambda / \beta \cos \theta$

where $\mathrm{K}$ is the Scherrer constant and its value is 0 . $94, \lambda$ is the wavelength of the X-ray $(0.1542 \mathrm{~nm}) . \beta$ is the full width at half maximum in radians and $\theta$ is the Bragg angle. The average crystalline size of the nanoparticles was determined to be around $16 \mathrm{~nm}$ as shown in Table 1 which is also in agreement with the TEM results.

The FTIR spectrum (Fig. 8) of AgNPs synthesised using Padina Tetrastromatica shows a strong band at $3211 \mathrm{~cm}^{-1}$ attributes to the $\mathrm{O}-\mathrm{H}$ groups present in alcohols and phenols [19]. The peak at $2922 \mathrm{~cm}^{-1}$ designates the $\mathrm{C}--\mathrm{H}$ stretching vibrations. The absorption peak at $1627 \mathrm{~cm}^{-1}$ may be due to the amide group coming from the carbonyl group of proteins. The band located at $1333 \mathrm{~cm}^{-1}$ arises due to the $\mathrm{C}-\mathrm{N}$ stretching or the $\mathrm{O}-\mathrm{H}$ bending vibrations. The absorption peak at $1032 \mathrm{~cm}^{-1}$ illustrates the presence of carboxylic acid functional group. It is wellknown that proteins can bind to AgNPs through free carboxylate group [20]. The presence of bands at 1627 ,

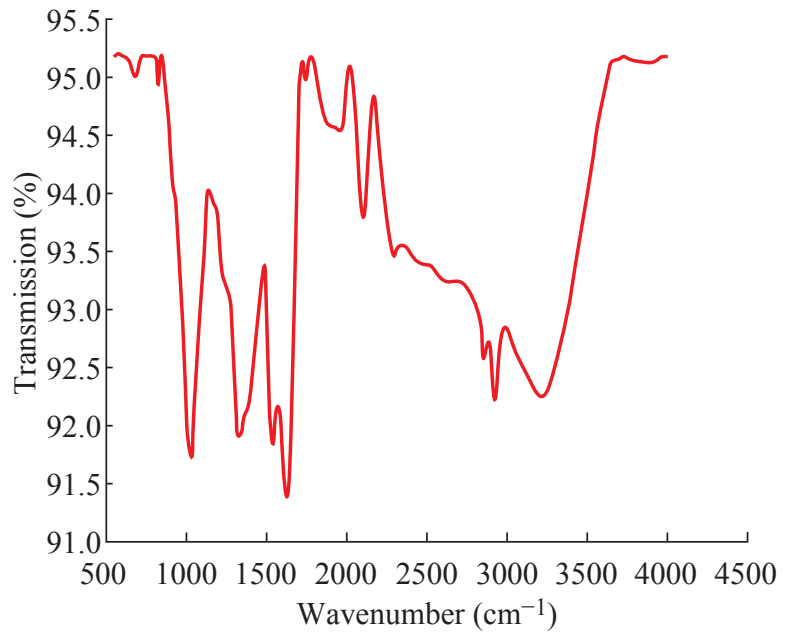

Fig. 8 FTIR spectrum of biosynthesised AgNPs.

1333 and $1032 \mathrm{~cm}^{-1}$ indicates that AgNPs are possibly bound to proteins through carboxylate group. But the exact nature and chemical composition of compounds involved in the reduction as well as stabilization of AgNPs needs a detailed investigation.

\section{Antibacterial activity}

The AgNPs shows excellent antibacterial activity against both the tested pathogens E.coli and A.hydrophila. Clear zones of inhibition of bacterial growth on nutrient agar plates around the disks impregnated with test AgNPs are shown in Fig. 9. A. hydrophila has maximum zone of inhibition of 24 $\mathrm{mm}$ and E.Coli has a zone of inhibition of $21 \mathrm{~mm}$. No clear zone of inhibition was observed for the controls seaweed extract and $1 \mathrm{mM} \mathrm{AgNO}_{3}$. The small size and large surface area to volume ratio of the AgNPs may favour its bactericidal activity [21].

\section{Catalytic activity of AgNPs for the degradation of methylene blue}

Due to the pollution problems caused by the highly stable and toxic dye molecules like Methylene blue (MB), its degradation and removal are of great interest.

Table 1 Calculation of the average particle size of biosynthesized AgNPs using Debye Scherer's equation

\begin{tabular}{cccccc}
\hline Sl. No. & $2 \theta$ (degrees) & d-spacing $(\mathrm{nm})$ & FWHM & $\mathrm{B}=\Pi * \mathrm{FWHM} / 180($ radians $)$ & $\mathrm{D}=\mathrm{k} \lambda / \beta \cos \theta(\mathrm{nm})$ \\
\hline 1 & 38.2641 & 0.235224 & 0.5510 & 0.0096 & 15.72 \\
2 & 44.3399 & 0.196338 & 0.7872 & 0.0137 & 10.75 \\
3 & 64.6646 & 0.144146 & 0.6298 & 0.0109 & 21.84 \\
4 & 77.5847 & 0.122953 & 1.1520 & 0.0201 & 15.69 \\
& \multicolumn{2}{r}{ The average crystalline size of biosynthesized AgNPs is found to be $16 \mathrm{~nm}$} \\
\hline
\end{tabular}




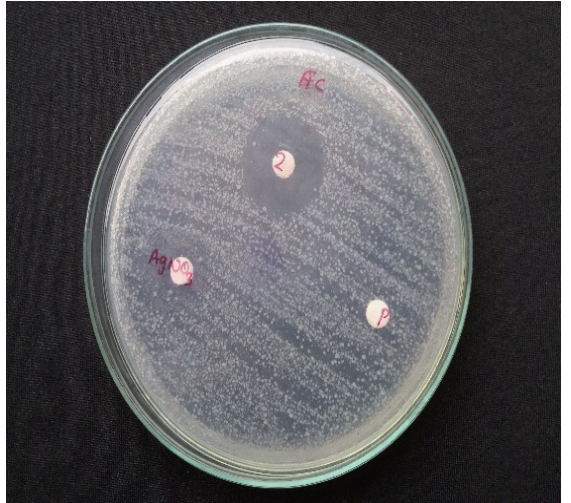

(a)

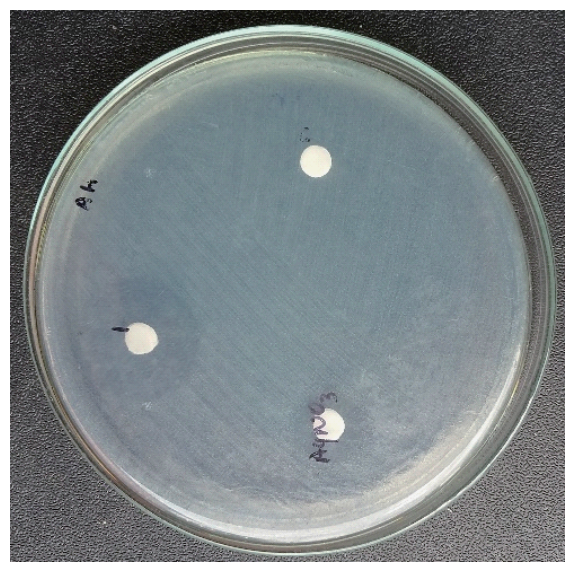

(b)

Fig. 9 Antibacterial activity of biosynthesized AgNPs against (a) E.coli and (b) A.hydrophila.

The catalytic performance of AgNPs was evaluated using the reduction reaction of $\mathrm{MB}$ by $\mathrm{NaBH}_{4}$. $\mathrm{MB}$ is a cationic phenothiazine dye widely used in textile industry and forms a major dye pollutant. The aqueous solution of MB is deep blue in colour and in the UVVis absorption spectrum it shows a strong absorption band at $664 \mathrm{~nm}$ with a hump at $614 \mathrm{~nm}$ due to $\mathrm{n} \rightarrow \Pi^{*}$ transition [22]. The reduction of MB into its colourless form (Leuco Methylene Blue) can be easily followed spectrophotometrically by monitoring the absorption maximum at $664 \mathrm{~nm}$.

The intensity of the peak at $664 \mathrm{~nm}$ remains almost unchanged for several hours in the absence of AgNPs catalyst demonstrating that the reduction of MB by $\mathrm{NaBH}_{4}$ is insignificantly slow due to the appreciable difference in redox potentials of $\mathrm{MB}$ and $\mathrm{NaBH}_{4}$. Thus this reaction is not kinetically favourable in the absence of the catalyst and could not be realized only with the reducing agent $\mathrm{NaBH}_{4}$. But the degradation reaction started immediately upon the addition of the silver nanocatalyst. This is evident from the fading and complete bleaching of the deep blue colour of the MB as well as the decrease in intensity of the peak at
$664 \mathrm{~nm}$ indicating hypochromic shift (Fig. 10 (a)). The reaction was found to be completed in $12 \mathrm{~min}$ as was evident from almost zero absorption at $664 \mathrm{~nm}$. Here the AgNPs act as an electron transfer mediator between $\mathrm{MB}$ and $\mathrm{NaBH}_{4}$. The catalytic reduction proceeds on the surface of the AgNPs. As soon as the electron donor $\left(\mathrm{BH}_{4}^{-}\right)$and electron acceptor (MB) get adsorbed on the surface of the AgNPs, catalytic reaction starts by the transfer of electron from $\mathrm{BH}_{4}^{-}$to MB. Thus, AgNPs help in facilitating the reduction of MB by lowering the activation energy of the reaction and hence play the role of a catalyst [23].

The kinetics of this reaction was studied spectrophotometrically by monitoring the absorption peak at $664 \mathrm{~nm}$. Since the concentration of $\mathrm{NaBH}_{4}(0.06$ $\mathrm{M})$ used in this reactions is much higher than that of MB $(0.08 \mathrm{mM})$, its concentration remains practically constant throughout the course of the reaction and hence the reaction may be considered to be pseudo-first order. Therefore, the reaction kinetics can be ascribed as:

$-k t=\ln \left(C / C_{o}\right)$

where $\mathrm{k}$ is the pseudo first-order rate constant, $\mathrm{t}$ is the reaction time; $\mathrm{C}$ and $\mathrm{C}_{\mathrm{o}}$ are the concentrations of
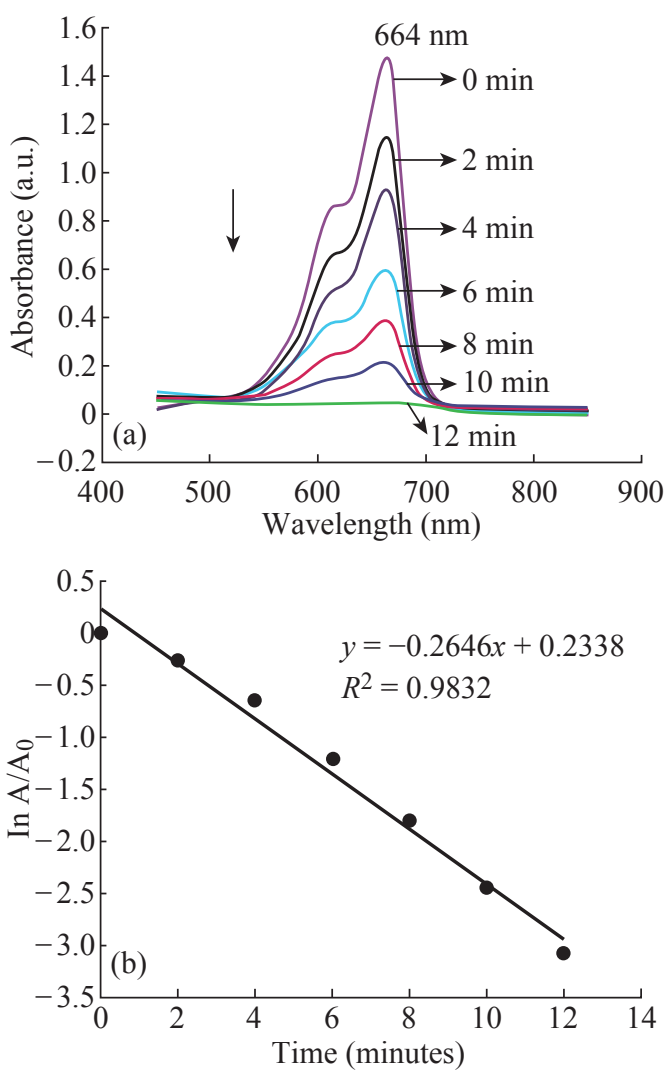

Fig. 10 (a) UV-vis. absorption spectra for the degradation of MB (b) Plot of $\ln \left(\mathrm{A} / \mathrm{A}_{\mathrm{o}}\right)$ versus reaction time. 
$\mathrm{MB}$ at time $\mathrm{t}$ and at initial time respectively. Since the absorbance is proportional to concentration of solution, the absorbance at time $\mathrm{t}(\mathrm{A})$ and time $0\left(\mathrm{~A}_{\mathrm{o}}\right)$ are equivalent to concentration at time $\mathrm{t}(\mathrm{C})$ and time 0 $\left(\mathrm{C}_{\mathrm{o}}\right)$ respectively [24].

A good linear relationship between $\ln \left(\mathrm{A} / \mathrm{A}_{\mathrm{o}}\right)$ and reaction time $t$ was obtained for the reduction reaction catalysed by AgNPs (Fig. 10 (b)). The rate constant (k) for the degradation of MB was found to be 0.2646 $\min ^{-1}$ which is directly obtained from the slope of the linear plot. Thus the biosynthesised AgNPs act as efficient catalyst for the degradation reactions of toxic chemicals like MB and can be successfully applied for waste water treatment.

\section{Conclusions}

In this study we have successfully synthesised AgNPs biometrically using aqueous extract of seaweed Padina Tetrastromatica which is proved to be an efficient, eco-friendly and simple method. The nanoparticles were characterized by UV-Visible Spectroscopy, HR-TEM, SAED, XRD and FTIR techniques. The UV-Visible spectral analysis exhibited a peak at $424 \mathrm{~nm}$ which confirmed the surface plasmon resonance of biosynthesised AgNPs. Crystalline nature of AgNPs is evident from the characteristic peaks in the XRD pattern, bright circular spots in the SAED pattern and clear lattice fringes in the HRTEM images. The morphology of the synthesised nanoparticles was almost spherical with an average size of $15 \mathrm{~nm}$ as revealed from TEM analysis. FTIR studies confirmed the involvement of various bioactive metabolites in the seaweed extract in the synthesis and stabilization of nanoparticles. The biosynthesized AgNPs exhibited significant antimicrobial activity against A.hydrophila and E.coli. The biosynthesized AgNPs was also found to be highly efficient towards the degradation reaction of $\mathrm{MB}$ by $\mathrm{NaBH}_{4}$. The reaction followed pseudo-first order kinetics and the rate constant was found to be $0.2646 \mathrm{~min}^{-1}$. Thus the green synthesised AgNPs are expected to be a promising candidate for environmental bioremediation as well as biomedical applications.

\section{Acknowledgments}

One of the authors Ms. Princy. K.F would like to gratefully acknowledge the University Grants Commission (UGC), New Delhi, for the Junior Research Fellowship. The authors are pleased to acknowledge STIC, KOCHI, School of Pure and Applied Physics, M.G. University and Marine Biotechnology Centre, Chemical Oceanography Department, National Centre for Aquatic Animal Health, CUSAT for characterization studies.

\section{References}

[1] P.K. Jain, X. Huang, I.H. El-Sayed, et al., Noble metals on the nanoscale: optical and photothermal properties and some applications in imaging, sensing, biology, and medicine. Acc Chem Res., 2008, 41: 1578-1586.

[2] V.K. Sharma, R.A. Yngard, Y. Lin. Silver nanoparticles: green synthesis their antimicrobial activities. Adv. Colloid Interface Sci., 2009, 145: 83-96.

[3] K. Gopinath, S. Gowri, A. Arumugam. Phytosynthesis of silver nanoparticles using Pterocarpus santalinus leaf extract and their antibacterial properties. J. Nanostr. Chem., 2013, 3: 1-7.

[4] D. Philip. Green synthesis of gold and silver nanoparticles using Hibiscus Rosa sinensis. Physica E., 2010, 42: 14171424.

[5] K.B. Narayanan, N. Sakthivel. Extracellular synthesis of silver nanoparticles using the leaf extract of Coleus amboinicus Lour. Mater. Res. Bull., 2011, 46: 1708-1713.

[6] S. Shivshankar, A. Rai, A. Ahmad et al. Rapid synthesis of $\mathrm{Au}, \mathrm{Ag}$, and bimetallic $\mathrm{Au}$ core-Ag shell nanoparticles using Neem (Azadirachta indica) leaf broth. J. Colloid Interface Sci., 2004, 275: 496-502.

[7] T. Stalin Dhas, V. Ganesh Kumar, V. Karthick, et al. Facile synthesis of silver chloride nanoparticles using marine alga and its antibacterial efficacy. Spectrochimica Acta Part A: Molecular and Biomolecular Spectroscopy., 2014, 120: 416-420.

[8] J.R. Morones, J.L. Elechiguerra, A. Camacho, et al., The bactericidal effect of silver nanoparticles. Nanotechnology., 2005, 16: 2346-2353.

[9] D. Sannino, V. Vaiano, O. Sacco, et al., Mathematical modelling of photocatalytic degradation of methylene blue under visible light irradiation. J. Environ. Chem. Eng., 2013, 1: 56-60.

[10] K.T. Chung, C.E. Cerniglia. Mutagenicity of azo dyes: structure-activity relationships. Mutat. Res., 1992, 277 : 201-220.

[11] S.K. Ghosh, S. Kundu, M. Mandal et al., Silver and gold nanocluster catalysed reduction of methylene blue by arsine in a micellar medium. Langmuir, 2002, 18: 87568760.

[12] M.R. Kim, D.K Lee, D.J. Jang. Facile fabrication of Pt/ $\mathrm{Ag}$ nanocomposites having enhanced catalytic properties. Appl. Catal. B Environ., 2011, 103: 253-260.

[13] Y. Zheng, A. Wang. Ag nanoparticle-entrapped hydrogel as promising material for catalytic reduction of organic dyes. J. Mater. Chem. 2012, 22: 16552-16559.

[14] Y. Melpha, N. Manchu, J. Edwin James. Phytochemical evaluation of two brown seaweeds from Muttom and Rasthacaud coasts of Tamil Nadu, India. J. Chem. Pharm. Res., 2014, 6(10): 566-569.

[15] T.N.V.K.V. Prasad, V.S.R. Kambala, R. Naidu: Phyconanotechnology: Synthesis of silver nanoparticles using brown marine algae Cystophora moniliformis and their characterization. J. Appl. Phycol., 2013, 25: 177182.

[16] P. Mulvaney. Surface Plasmon spectroscopy of nanosized metal particles. Langmuir. 1996, 12: 788-800.

[17] R.R.R Kannan, W.A. Stirk, J. Van Staden. Synthesis of silver nanoparticles using the seaweed Codium capitatum 
P.C Silva (Chlorophyceae). South African Journal of Botany, 2013, 86: 1-4.

[18] V. Kathiravan, S.Ravi, S. Ashokkumar. Synthesis of silver nanoparticles from Melia dubia leaf extract and their in vitro anticancer activity. Spectrochimica Acta Part A: Molecular and Biomolecular Spectroscopy., 2014, 130: 116-121.

[19] K. Jilie, Y.U. Shaoning. Fourier Transform Infrared Spectroscopic Analysis of Protein Secondary Structures. Acta Biochim Biophys Sin., 2007, 39: 549-559.

[20] S.L. Smitha, D. Philip, K.G. Gopchandran, Studies on surface Plasmon resonance and photoluminescence of silver nanoparticles. Spectrochim. Acta A, 2008, 71: 186190

[21] C. Baker, A. Pradhan, L. Pakstis et al. Synthesis and antibacterial properties of silver nanoparticles. J. Nanosci. Nanotechnol. 2005; 5: 244-249.

[22] I. Laoufi, R. Lazzari, J. Jupille, et al. Size and Catalytic Activity of Supported Gold Nanoparticles: An in
Operando Study during CO Oxidation. J. Phys. Chem. C 2011, 115: 4673-4679.

[23] S.A. Aromal. D. Philip. Green synthesis of gold nanoparticles using Trigonella foenum-graecum and its size-dependent catalytic activity. Spectrochim. Acta A, 2012, 97: 1-5.

[24] M.R. Bindhu, M. Umadevi. Antibacterial and catalytic activities of green synthesized silver nanoparticles. Spectrochimica Acta Part A: Molecular and Biomolecular Spectroscopy, 2015, 135: 37-378.

Copyright $\subset 2016$ Kaithavelikkakath Francis Princy, Sarasan Manomi, Rosamma Philip and Anu Gopinath. This is an openaccess article distributed under the terms of the Creative Commons Attribution License, which permits unrestricted use, distribution, and reproduction in any medium, provided the original author and source are credited. 